\title{
Vorurteilsbereitschaft und autoritäres Verhalten
}

Eine empirische Untersuchung an 9- bis 12jährigen Grund- und Hauptschülern

\author{
Dissertation \\ zur Erlangung des sozialwissenschaftlichen \\ Doktorgrades der Wirtschafts- und Sozialwissen- \\ schaftlichen Fakultät der Georg-August-Univer- \\ sität zu Göttingen
}

$\underset{\text { von }}{\text { vorgelegt }}$

Jürgen Körner aus Erfurt

Göttingen 1975 
ISBN 978-3-476-99844-6 ISBN 978-3-476-99843-9 (eBook) DOI 10.1007/978-3-476-99843-9

Berichterstatter: Professor Dr. Ernst-August Roloff Mitberichterstatter: Professor Dr. Peter Faßheber

Tag der mündlichen Prüfung: 5. 2.1976 


\section{Inhaltsverzeichnis}

\section{Vorwort 5}

1. Überlegungen zum Problemgegenstand 7

1.1. Einleitung 7

1.2. Ideengeschichte des Vorurteils 11

1.3. Vorurteilsbereitschaft als Gegenstand politischer Psychologie in den USA und in der BRD 18

1.4. Einzelwissenschaftliche Zugangsweisen 27

1.4.1. Vorbemerkungen 27

1.4.2. Abgrenzung verwandter Begriffe 28

1.4.3. Systematik der Definitionsversuche 29

1.4.3.1. Welches sind die Objekte des Vorurteils? 30

1.4.3.2. Sind Vorurteile immer negative Aussagen? 31

1.4.3.3. Sind Vorurteile universell? 34

1.4.3.4. Sind Vorurteile immer falsche Aussagen? 35

1.4.4. Psychoanalyse der Vorurteilsbereitschaft 37

1.4.4.1. Individualpsychologische Aspekte:

Die Persönlichkeit des Vorurteilsvollen 38

1.4.4.2. Sozialpsychologische Aspekte:

Genese der Vorurteilsbereitschaft 39

1.4.4.3. Vorurteilstheorie der Frankfurter Schule 43

1.5. Allgemeine methodische Überlegungen 51

2. Empirische Untersuchungen 56

2.1. Fragestellung 56

2.2. Gang der Darstellungen 57

2.3. Vorurteilsbereitschaft als isoliertes Merkmal 58

2.3.1. Konstruktion der Skala »Vorurteile« 58

2.3.2. Methodisch begründete Einschränkungen 60

2.3.3. Faktorenanalysen der Skala »Vorurteile« 61

2.3.4. Gruppierung der Ergebnisse nach Alter und

Schichtzugehörigkeit 61

2.3.4.1. Altersspezifische Ergebnisse 61

2.3.4.2. Schichtenspezifische Ergebnisse 62 
2.3.5. Zusammenfassung der Ergebnisse zur Vorurteilsbereitschaft 64

2.4. Vergesellschaftung der Vorurteilsbereitschaft mit anderen Merkmalen 66

2.4.1. Konstruktion fünf weiterer Skalen 66

2.4.1.1. Ziele und Methoden 66

2.4.1.2. Exkurs: Die Skalen »efficacy« und

»Demokratie « 68

2.4.1.3. Die übrigen Skalen 69

2.4.2. Ergebnisse der fünf Skalen 72

2.4.2.1. Globale Analyse über alle Skalen 73

2.4.2.2. Einzelanalysen der Skalen 73

2.4.2.3. Altersspezifische Ergebnisse 74

2.4.2.4. Schichtenspezifische Ergebnisse 75

2.4.3. Vergesellschaftung der Merkmale zu einem Syndrom 77

2.4.3.1. Interrelationen der Merkmale 78

2.4.3.2. Faktoranalytische Gruppierungen 79

2.4.3.3. Kanonische Korrelation 79

2.5. Zusammenfassung der Kinder-Untersuchung 80

2.6. Untersuchung einer ausgelesenen Väter-Stichprobe 83

2.6.1. Gegenstand der Untersuchungen 83

2.6.2. Ziele und Methoden 85

2.6.3. Begründung der Skalen 86

2.6.4. Ergebnisse 88

2.6.4.1. Globale Analyse der Väter-Befragung 89

2.6.4.2. Unterschiede zwischen den Extremgruppen 90

2.6.4.3. Zusammenhänge zwischen Vätern und Kindern 91

2.6.5. Zusammenfassung der Väter-Untersuchung 91

3. Gesamtdiskussion 94

3.1. Überblick über die Ergebnisse 94

3.1.1. Vorurteilsbereitschaft bei 9- bis 12 jährigen Kindern 94

3.1.2. Vergesellschaftung der Merkmale im autoritären Syndrom 96

3.1.3. Genese des autoritären Syndroms in der Vater-KindDyade 98

3.2. Zur Kritik des Subjekts 101

3.3. Vorurteilsbekämpfung in der Schule 104

Anmerkungen 109

Literaturverzeichnis 126

Anhang 133 